\title{
Molecular Dynamics Simulations of Hot Fluids: From Speciation to Thermodynamics
}

\author{
YUAN MEI ${ }^{1}$, WEIHUA LIU ${ }^{1}$ AND JOËL BRUGGER ${ }^{2}$ \\ ${ }^{1} \mathrm{CSIRO}$ \\ ${ }^{2}$ Monash University \\ Presenting Author: yuan.mei@csiro.au
}

Metals are transported within the deep Earth at high pressure and temperature by fluids possessing a complex chemical makeup. Reliable knowledge of metal behaviour in ore-forming fluids is essential for understanding the enrichment, transport and precipitation of metals and the formation of ore deposits: we can only predict how fluids of different compositions, pressures, and temperatures transport metals if reliable thermodynamic properties are available. In the past decade, ab initio molecular dynamics simulations became increasingly accurate due to the advance of supercomputers, and this has dramatically improved our understanding of the chemical processes of metal transport in hot fluids.

$A b$ initio molecular dynamics (MD) simulations, whereby interatomic interactions are described by quantum mechanics in the form of density functional theory, provide a means to determine the speciation and hydration properties of metal complexes under conditions that are beyond experimental practicality. The advances of enhanced sampling approach allow us to calculate the free energy of chemical reactions from constrained $\mathrm{MD}$, and then to derive thermodynamic properties for metal complexation reactions. The predicted thermodynamic properties can be extrapolated to a wide range of T-P and incorporated into geochemical modelling software. In the past years, we have employed ab initio MD to refine thermodynamic properties of $\mathrm{Cu}-\mathrm{Cl} / \mathrm{HS}^{[1]}, \mathrm{Zn}-\mathrm{Cl} / \mathrm{HS}^{[2,3]}, \mathrm{Pd}-\mathrm{Cl} / \mathrm{HS}^{[4]}, \mathrm{HCl}^{[5]}$, and create new properties for $\mathrm{Au}-\mathrm{NH}_{3} / \mathrm{OH}^{[6]}$ and $\mathrm{W}-\mathrm{F}$ complexes. The MD-based thermodynamic properties have been successfully applied in geochemical models of ore-forming processes ${ }^{[7]}$.

Reference:

1. Mei, Sherman, Liu \& Brugger (2013), Geochimica et Cosmochimica Acta, 102 (0), 45-64.

2. Mei, Sherman, Liu, Etschmann, Testemale \& Brugger (2015), Geochimica et Cosmochimica Acta, 150 (0), 265-284.

3. Mei, Etschmann, Liu, Sherman, Testemale \& Brugger (2016), Geochimica et Cosmochimica Acta 2016, 179, $32-52$.

4. Mei, Etschmann, Liu, Sherman, Barnes, Fiorentini, Seward, Testemale \& Brugger (2015) Geochimica et Cosmochimica Acta, 161 (0), 128-145.

5. Mei, Liu, Brugger, Sherman \& Gale (2018), Geochimica et Cosmochimica Acta, 226, 84-106.

6. Mei, Liu, Brugger \& Guan (2020) Geochimica et Cosmochimica Acta 291, 62-78.

7. Zhong, Brugger, Chen \& Li (2015) Chemical Geology, 395, 154-164. 